\title{
Association Between Functional Disability and Depressive Symptoms Among Older Adults in Rural China: A Cross-Sectional Study
}

Jian Rong

Anhui Medical University

Yanhong Ge

Anhui Medical University

Xueqin Wang

Anhui Medical University

Guimei Chen

Anhui Medical University

Hong Ding ( $\nabla$ dinghong2003@126.com )

Anhui Medical University https://orcid.org/0000-0003-1448-1434

Research article

Keywords: Functional disability, Older adults, Depressive symptoms, Rural China

Posted Date: July 1st, 2020

DOl: https://doi.org/10.21203/rs.3.rs-37157/v1

License: (9) This work is licensed under a Creative Commons Attribution 4.0 International License.

Read Full License 


\section{Abstract}

Background: The association between functional disability and depressive symptoms among elderly people in rural China is not clear. This study explored the relationship between functional disability and depressive symptoms, focusing on whether an interactive association between functional disability, demographic characteristics and depressive symptoms exists among older adults in rural Anhui, China.

Methods: A cross-sectional survey study was conducted with multi-stage stratified random sampling. The 30-item Geriatric Depression Scale and WHO Disability Assessment Schedule 2.0 were used to evaluate depressive symptoms and functional disability, respectively. The data were analyzed using SPSS statistics 25.0 program with chi-square test, Mann-Whitney $U$ test, binary logistic regression analysis, and classification and regression tree model.

Results: The prevalence of depressive symptoms in 3336 older people was $52.94 \%$. After adjustment, subjects who had problems in participation (adjusted odds ratio $[A O R]=3.499,95 \%$ confidence interval [Cl]:2.385-4.987), life activities ( $A O R=1.683,95 \% \mathrm{Cl}: 1.370-2.066)$, getting along ( $A O R=1.616,95 \% \mathrm{Cl}$ : 1.299-2.010), and mobility ( $\mathrm{AOR}=1.842,95 \% \mathrm{Cl}: 1.503-2.258$ ) had an increased depressive symptoms risk. However, cognition (AOR=0.785, 95\% Cl: 0.647-0.953) negatively correlated with depressive symptoms. Additionally, the interactive association between functional disability dimensions, various variables and depressive symptoms were identified for the first time. Those who had problems in mobility, getting along and were unemployed, the possibility of having depressive symptoms was the highest.

Conclusions: Special attention should be paid to unemployed older adults, and those with problems in participation, life activities, getting along, and mobility and no problems in cognition to maintain a good psychological state. Our findings may be greatly significant for developing more targeted and effective mental health prevention and intervention measures for older adults in rural areas.

\section{Background}

With the development of China's economy and the change of population structure, the process of aging is developing rapidly. By the end of 2019, China had a population of 253.88 million aged 60 or above, accounting for $18.1 \%$ of the total population [1]. It was predicted that the proportion of older adults aged 60 and over will reach $35.1 \%$ of the total population by 2050 [2]. With this rapid growth, the mental disorder related to aging has attracted an increasing number of policy makers and health managers in China [3].

Depression is a common mental disorder in the elderly and has developed into an important public health problem [4]. Patients with depression are characterized by listlessness, lack of interest in normal life, and mental retardation and accompanied by fatigue, weight change, and inattention [5]. The global prevalence of depression in the elderly varies between $10 \%$ and $20 \%$ [6] and with different demographic characteristics [7]. Our previous meta-analysis found that the prevalence of depressive symptoms among the elderly aged 60 and over in China from 2010 to 2019 was $25.55 \%$, especially in rural areas, the 
prevalence reached 31.02\% [8]. Studies have shown that depressive symptoms have increased the risk of death and suicide, putting tremendous financial burden on families and the society [9]. A study in Germany found that the total cost of caring for older adults with depression for 6 months is 3748 euros [10]. Furthermore, depression was probably a precursor of Alzheimer's disease, easily leading to dementia in older adults [11]. Additionally, it was predicted that depression will become the second leading cause of disability worldwide by 2020 [12]. Therefore, it is of great practical significance to identify factors related to depressive symptoms for centralized screening and subsequent development of preventive interventions. Studies have indicated that the complex interaction of social, psychological, and biological factors can lead to depressive symptoms, including marital status, family income level, and personal education level [13-15]. Many bad lifestyles also increase the risk of prevalence, such as smoking, alcoholism, and lack of physical exercise $[16,17]$.

Studies have shown that functional disability of the older adults is a major public health problem in many countries, including China [18]. Functional disability in the elderly has not only a negative impact on independent living ability but also reduces the quality of life [19]. Approximately $15.0 \%$ of the world's population has different degrees of functional disability [20]. There are differences in functional disability prevalence among countries. A large-scale national cross-sectional survey in Morocco showed that the overall functional disability prevalence of older adults was 9.5\% [21]. A Dutch study showed that the prevalence of functional disability in the elderly was $22 \%$ [22]. According to the data analysis of Behavioral Risk Factors Surveillance System in 2016 by Centers for Disease Control in the United States, the prevalence of mobile disability in the elderly was $26.9 \%$ [23]. The prevalence of functional disability in the elderly in Asia varies from $16.2 \%$ in China to $55.7 \%$ in India [24]. Several domestic and foreign studies have found that increasing age [25], poor health [26], and weakness [27] were associated with functional disability.

Studies have shown that functional disability was a related factor for depressive symptoms, but most studies were based on the Western population and mainly aimed at revealing the related factors of depressive symptoms among older adults [18, 28, 29]. However, epidemiological evidence for the association between functional disability and depressive symptoms continue to remain insufficient, especially for the vulnerable group, i.e., the elderly in rural areas in China. However, a comprehensive understanding of factors related to depressive symptoms is of great theoretical and practical significance for the formulation of specific and appropriate intervention strategies to reduce the occurrence of depressive symptoms in the elderly. It can provide empirical reference for China's rural areas and other developing countries to further improve the mental health of rural area-based elderly and promote grassroots public health services. In this context, this study explored the relationship between functional disability and depressive symptoms of the elderly in the rural areas of Anhui Province, China, with a focus on whether there is an interactive association between functional disability, demographic characteristics and depressive symptoms.

\section{Methods}




\section{Study design and sample}

To obtain a better representative sample, this cross-sectional survey was conducted using a multi-stage sampling survey method from January through July 2018. First, we selected three prefecture-level cities from the 16 prefecture-level cities in Anhui Province: Fuyang (North); Hefei (central, the capital of Anhui provincial), and Anqing (South). Second, in each prefecture-level city, one county was randomly selected. Next, in each selected county, two townships were randomly selected. A total of six townships were finally selected. At the last stage, we randomly selected three villages in each selected township, and a total of 18 villages were identified as the survey sites.

According to the data of local household registration system, 50 poor households were randomly selected from each selected village based on the list of poor households, and 75 non-poor households were randomly selected from the neighbors of poor households. The elderly (aged $\geq 60$ ) from poor and nonpoor households were selected as the survey subjects. With the assistance of local community workers and village doctors, each subject was investigated in the form of a household survey, and a face-to-face interview was conducted by the graduate students from Anhui Medical University who had received unified training using a structured questionnaire. The purpose and procedures of the study were dictated to all respondents, and informed consent was signed before the survey. Persons aged 60 and over and living in their residence for at least one year participated in the survey. Individuals with cognitive impairment, with language communication disorders, who were deaf, and with lack of access during the survey were excluded.

A total of 3491 older adults participated in the survey, and 155 older adults who were exhausted or occupied and could not complete the questionnaire were excluded. Finally, 3336 older adults were included for further analyses, with an effective response rate of $95.56 \%(3336 / 3491)$.

\section{Assessment instruments}

\section{0-item Geriatric Depression Scale(GDS-30)}

Depressive symptoms were evaluated using GDS-30, which was specifically designed for screening depressive symptoms in older adults [30]. This scale comprises 30 items; each item is dichotomized into two categories: "Yes" or "No". Among the 30 items, 10 items were scored in reverse order (1 point for "No" and 0 point for "Yes"), and the remaining were scored in positive order (1 point for "Yes" and 0 point for "No"). The total score ranged from 0 to 30 points, and the clinical boundary was 10 points. An individual with a GDS-30 score $\leq 10$ was regarded as non-depressive and with a GDS-30 score $\geq 11$ as depressive [31]. Studies have confirmed that GDS-30 had a high sensitivity $(70.6 \%)$ and high specificity $(70.1 \%)$ in a Chinese population aged 60 and over [32]. In this study, the internal consistency of GDS-30 is as indicated by the Cronbach's a score of 0.890 .

\section{WHO Disability Assessment Schedule (WHODAS 2.0)}


WHODAS 2.0 was employed to examine the functional disability of the respondents. The scale consists of 36 items, including 6 dimensions: (1) cognition, (2) mobility, (3) self-care, (4) getting along, (5) life activities, and (6) participation. Each item is scored on the Likert 5 scale $(1=$ no difficulty, $2=$ mild difficulty, 3 = moderate difficulty, $4=$ severe difficulty, $5=$ extreme difficulty). According to the scale instruction manual [33], we recoded the scores of each item, calculated each evaluation dimension and the overall score, and converted the original score to correspond to points 0-100 $(0=$ no disability, $100=$ complete disability). Based on the International Classification of Functioning (ICF) disability and health criteria, each evaluation dimension and overall disability level was evaluated, i.e., $<4$ points are classified as no problem disability status and $>4$ points as mild or above disability status [34]. The internal consistency of the schedule is as indicated by the Cronbach's a score of 0.967 in this study.

\section{Demographic Characteristics}

The survey also collected demographic characteristic variables. These variables included gender (male, female), age (60-69, 70-79, $\geq 80$ ), educational level (illiterate and primary school and above), employment status (unemployed, employed), living style (living alone, living with spouse, others refer to living with children or other relatives), region (northern, central, southern), poverty (families whose annual per capita income was lower than the national poverty line need to be recognized by the Poverty Alleviation Office and other departments). Simultaneously, we also investigated the variables related to health status, including whether they had physical discomfort during the previous two weeks (Yes, No), chronic disease diagnosed by doctors (No, Yes), or were hospitalized in the previous year (Yes, No).

\section{Statistical analysis}

Descriptive statistics were used to assess the sample demographic characteristics (frequency and percentages). Median and interquartile ranges (IQR) were measured as the data showed skewed distribution. Mann-Whitney $U$ tests were employed to compare the functional disability of subjects with different depressive symptoms. The chi-squared tests were also employed to examine the difference between different depressive symptoms groups.

Binary logistic regression analysis with an enter method was used to explore the relationship between functional disability and depressive symptoms after adjusting for potential covariates (including gender, age, educational level, employment status, living style, region, poverty, physical discomfort, chronic diseases, and hospitalization). According to the criteria of tolerance and variance inflation factor, there was no multi-co-linearity between independent variables (Table S1 and Table S2). For functional disability variables, subjects who had no problem in each dimension were grouped as the reference group in a logistic regression model. For other variables, subjects who were male, aged 60-69 years, illiterate, unemployed, living alone, belonging to the northern region, poor, had physical discomfort, had no chronic disease, hospitalized were grouped as reference. The results of the binary logistic regression analysis were expressed with the adjusted odds ratio (AOR) and associated $95 \%$ confidence interval $(95 \% \mathrm{Cl})$. 
To further investigate the interactive association between functional disability, relevant factors and depressive symptoms, a classification and regression tree model (CART) was used. This model is a novel analysis method, which can automatically judge and classify according to the significance of the test, optimal segment many types of variables and samples, and show the interaction between different variables through the tree diagram. It can also overcome the co-linearity problem that exists in the traditional analysis method and investigate the complex combination or interaction between the factors and variables neglected in the traditional analysis method [35]. The CHAID algorithm was used to screen variables and include statistically significant variables in univariate analysis. Additionally, to fully mine the interaction between variables and keep the tree structure relatively simple, the minimum cases in the parent node and child node of the model parameters were set 400 and 200, respectively, and the maximum growth depth was 3 .

All data were analyzed using SPSS statistics software, version 25.0 (IBM, Armonk, NY, USA). A two-tailed $p<0.05$ was considered to be statistically significant.

\section{Results}

\section{Sample characteristics}

The demographic characteristics of respondents is shown in Table 1. Age distribution of 3336 respondents included in the analysis ranged from 60 to 97 years, and median (IQR) was $70(65.25,76)$. Most of the respondents were female (50.8\%), illiterate (66.3\%), unemployed (64.1\%), living with spouse (43.0\%), belonging to the northern (44.4\%), non-poor (63.8\%), had physical discomfort (63.5\%), had chronic diseases (74.1\%) and hospitalized (68.2\%). Except for living style, there was a statistically significant difference in depressive symptoms among demographic variables (all $p<0.05$ ).

\section{Overview of depressive symptoms}

Among the 3336 elderly people participants, 1766 (52.94\%) had depressive symptoms. The average score of depressive symptoms of the elderly was 12.4 points, with median (IQR) $11(7,18)$ points, and the high frequency scores of GDS-30 were concentrated between 4 and 15 points (Figure 1).

\section{Distribution of functional disability among subjects}

The distribution of functional disability among subjects with different depressive symptoms is shown in Table 2. The subjects had the highest score in the dimension of living activities (31.91 points) and the lowest score in self-care (11.33 points). Compared with the group without depressive symptoms, the subjects with depressive symptoms had higher scores in cognition, mobility, self-care, getting along, life activities and participation, and the difference between the two groups was statistically significant (all $\mathrm{p}<0.05)$.

\section{Association between functional disability and depressive symptoms}


The association between functional disability and depressive symptoms is shown in Figure 2. Binary logistic regression was used with the presence of depressive symptoms (absence $=1$, presence $=2$ ) as the dependent variable, and each dimension of disability status (had no problem as the reference group) was taken as the independent variable. After adjustment, the results showed that compared with the reference group, subjects had problems in participation ( $A O R=3.499,95 \% \mathrm{Cl}$ : 2.385-4.987), life activities $(A O R=1.683,95 \% \mathrm{Cl}: 1.370-2.066)$, getting along (AOR=1.616, 95\% Cl: 1.299-2.010) and mobility $(A O R=1.842,95 \% \mathrm{Cl}: 1.503-2.258)$ that were related factors for depressive symptoms (all $\mathrm{p}<0.05$ ). However, problems in cognition ( $A O R=0.785,95 \% \mathrm{Cl}: 0.647-0.953$ ) was a protective factor for depressive symptoms $(p=0.015)$.

\section{Results of classification and regression tree model}

CART model was conducted with depressive symptom (absence $=1$, presence $=2$ ) as the dependent variable and the dimension of functional disability and demographic characteristics as the classification nodes. The results are shown in Figure 3. The model includes three depth, 13 nodes, including 7 terminal nodes. Depressive symptoms were mainly concerned with mobility, participation, life activities, getting along, and employment status. Among which, mobility was the first split factor associated with depressive symptoms. Moreover, the interactive association between functional disability and various variables were identified.

Among participants that had no problem in mobility (node 1) but in participation (node 4) and life activities (node 8 ) had a high rate of having depressive symptoms than those with no problem in life activities (node 7).

For those with no problems in mobility (node 1) and participation (node 3), the proportion of developing depressive symptoms was the least.

Those who had problems in mobility (node 2), getting along (node 6) and were unemployed (node 12), the possibility of having depressive symptoms was the highest (node 12).

\section{Discussion}

This study investigated the association between functional disability and depressive symptoms of elderly people in rural Anhui, China. The results showed that a relationship between functional disability and depressive symptoms. Specifically, subjects had problems in participation, life activities, getting along, and mobility and had no problem in cognition had an increased risk of depressive symptoms. Furthermore, we identified the interactive association between functional disability and other factors related to depressive symptoms for the first time.

\section{Prevalence of depressive symptoms}

In this study, we found that the prevalence of depressive symptoms was $52.94 \%$, which is the same as $53.8 \%$ reported in a cross-sectional survey in Shenzhen, southern China [36], but much higher than that of 
the elderly in Korea (30.3\%) and Mexico $(29.1 \%)$ [37,38]. The heterogeneity of the prevalence among elderly people in different countries be because of differences of national culture and historical background as well as differences in survey samples of different assess scales and social support systems of the elderly in different countries. This suggests that further population-based studies need to be performed in representative national samples.

\section{Association between functional disability and depressive symptoms}

We found that there were different results on the association between functional disability and depressive symptoms. This study found that there was a significant correlation between participation and depressive symptoms in the elderly and the risk of depressive symptoms was lower in the elderly with no problem in participation. Consistent with our research results, a study in Hong Kong found that a higher level of participation had a protective effect on depressive symptoms [39]. A cross-sectional study in Japan found that the participation of the elderly was significantly related to depressive symptoms, and living alone and low frequency of travel were risk factors for depressive symptoms in elderly people [40]. Previous study found that high participation can prevent the occurrence of depressive symptoms by examining the subjects in the Korean Longitudinal Study of aging between 2006 and 2012 [41]. As for the relationship between participation and depressive symptoms, the possible mechanism is when the elderly actively participate in social activities, such as contacts with friends and neighbors, they can enjoy close communication and interaction and the company of others and get a certain degree of social support, generate positive emotions, friendship and a sense of meaning and reduce their loneliness. Studies have shown that these positive emotions can help prevent depressive symptoms in the elderly [42,43].

We found that life activities was related to the presence of depressive symptoms, and after controlling for confounders, the elderly had problems in life activities had a higher risk of depressive symptoms. The results were similar to those of previous studies. Studies on the elderly in Europe, America, the Middle East and other Asian countries have shown that the risk of depressive symptoms was related to the defect of living activities [44]. Tomiokak et al [45] conducted a three-year follow-up survey on 6360 elderly people aged 65 and over in Japanese community and found that participation (such as community activities, voluntary activities) was related to the change of instrumental activities of daily living. Relatively complete mobility of physical activity (such as walking and riding) can affect the degree of participation. In the process of social participation, getting along and getting information (such as keeping healthy knowledge) among the elderly can regulate their feelings toward negative life events, and then affect their mental health.

Interestingly, this study found that there was a negative correlation between cognition and depressive symptoms, that is, the elderly with no problem in cognition were more prone to develop depressive symptoms. This is inconsistent with previous studies. Ismailz et al [46] believed that the two were closely related, such as there were some common clinical manifestations and risk factors for the two occur together. Larae et al [47] found that depression in elderly people was an important risk factor for cognitive impairment and significantly increased the risk of cognitive impairment. Younh et al [48] thought that the 
cognition of the elderly improved by improving depressive symptoms and promoting the mental health of the elderly; Del bruto $\mathrm{OH}$ et al [49] also showed that the cognition of the elderly in developing countries was related to depressive symptoms. However, a Chinese scholar have found that there was no correlation between cognition level and depressive symptoms of the elderly in pension institutions [50]. Galecr et al [51] have also found that there was no significant correlation between cognition and depressive symptoms in elderly people. Considering the reasons, it is possible that with the increase in the age of the elderly, the brain function significantly decreases, which leads to cognitive impairment itself, thereby interacting with the cognitive impairment associated with depressive symptoms. At present, there are few similar studies on the association between the between cognition and depressive symptoms, and we hope to explore the relationship in the future.

\section{Interactive association among variables}

In this study, the interactive association between functional disability and demographic characteristics related to depressive symptoms was explored for the first time. Most studies have found that low educational level [32], female sex [52], and increasing age [53] were related to the occurrence of depressive symptoms in the elderly population. Simultaneously, some studies have noted the impact of functional disability on the mental health of the elderly [54]. Although these analyses and the study of factors were meaningful, more comprehensive methods are needed to explore the degree to which the joint combination and interaction of related factors associated with depressive symptoms. In the current study, CART model was used to explore the interactive association between functional disability and various variables. It was found that the elderly with mobility problems, getting along problems, and were unemployed had the highest risk of depressive symptoms. Simultaneously, among the elderly who had no problems with mobility and participation, the incidence of depressive symptoms was the lowest. However, this interactive association cannot be observed in binary logistic regression analysis, which further shows the advantages of CART model. We confirmed for the first time the interactive association between functional disability and other variables related to depressive symptoms. These results help understand which of the elderly are to develop depressive symptoms, and help design specific and comprehensive intervention strategies to improve the mental health level of the rural elderly.

\section{Strengths and limitations}

Our study has several advantages. First, the sample response rate of is high, and the large-scale survey results with high response rate are very robust. Second, we use the CART model in the method, which can overcome the possible co-linearity between variables and automatically judge and classify them according to the significance of the test. It can not only explore the interactive relationship between multivariables, but also be displayed by intuitive tree graph. Third, this is the first study to explore the interactive association between functional disability and other variables related to depressive symptoms, which provides more insights for the formulation of effective measures to prevent the occurrence of depressive symptoms for the elderly. 
However, this study also has some limitations. First, because of the characteristics of a cross-sectional study, it is difficult to infer the causality between functional disability and depressive symptoms, and the cohort study design needs to be considered in future studies. Second, the sample of this study comes from Anhui Province, China. Due to the heterogeneity of economic level and cultural background, the extension of the research results to other regions or other countries is limited. Finally, the sample of elderly depressive symptoms was determined by GDS-30, without the diagnosis of clinical professionals, and it may thus overestimate the true level of depressive symptoms.

\section{Conclusions}

In the rural elderly population in Anhui Province, functional disability is significantly related to depressive symptoms, especially the problems of participation makes the rural elderly face a greater risk of depressive symptoms. Special attention should be paid to unemployed older adults with problems in participation, life activities, getting along, and mobility and no problems in cognition to ensure early screening of depressive symptoms, thereby maintaining a good psychological state. Our findings would help develop targeted intervention strategies to prevent depressive symptoms and reduce related negative effects on individuals, families and society.

\section{Abbreviations}

GDS-30: 30-item Geriatric Depression Scale; WHODAS 2.0: WHO Disability Assessment Schedule; CART: Classification and regression tree model

\section{Declarations}

\section{Ethics approval and consent to participate}

This study was conducted in accordance with the Declaration of Helsinki and was approved by the Research Ethics Committee of Anhui Medical University (AMUREC: 2019H016). All respondents were fully informed about the study purpose and methods and provided written consent form.

\section{Consent for publication}

Not applicable.

\section{Availability of data and materials}

Not applicable. The datasets generated during the study are not publicly available due to an ethical restriction but are available from the corresponding author on reasonable request.

\section{Conflicts of interest}

The authors declare that they have no conflict of interest. 


\section{Funding}

This research was funded by Research Projects of Humanities and Social Sciences in Colleges and Universities of Anhui Province (No. SK2018A0165) and Doctoral Fund Project of Anhui Medical University (No. XJ201545). The funders had no role in the design of the study and collection, analysis, and interpretation of data and in writing the manuscript.

\section{Author's contributions}

JR conceptualized the study. YG, XW, GC, contributed to the study design, data collection and data processing and statistical analysis. XW and $Y G$ contributed to the literature review. JR wrote the article. $J R, Y G$ and $H D$ revised the article. All authors reviewed the manuscript and approved the final manuscript.

\section{Acknowledgements}

The authors would like to appreciate the involvement of the participants who joined this study.

\section{Author details}

${ }^{1}$ Department of Health Service Management, School of Health Management, Anhui Medical University, Anhui, China. ${ }^{2}$ Department of Medical Engineering, The Second Hospital of Anhui Medical University, Anhui, China.

\section{References}

1. National Bureau of Statistics. (2020). Statistical bulletin for national economic and social development. Retrieved from: http://www.stats.gov.cn/tjsj/zxfb/202002/t20200228_1728913.html.

2. World Population Ageing 2017 Highlights. (2017). Retrieved from: https://www.un.org/en/development/desa/population/theme/ageing/WPA2017.shtml.

3. Huang Y, Wang Y, Wang H, Liu Z, Yu X, Yan J, et al. Prevalence of mental disorders in China: a crosssectional epidemiological study. Lancet Psychiatry. 2019;6(3):211-24.

4. Friske A, Wetherell JL, Gatz M. Depression in older adults. Annu Rev Clin Psychol. 2009;5(1):363-89.

5. World Health Organization. (2013). Depression. Retrieved from: https://www.who.int/healthtopics/depression\#tab=tab_1.

6. Blazer DG. Depression in late life: review and commentary. J Gerontol A Biol Sci Med Sci. 2003;58(3):249-65.

7. World Health Organization. Depression and Other Common Mental Disorders: Global Health Estimates. Geneva: World Health Organization; 2017.

8. Rong J, Ge YH, Meng NN, Xie TT, Ding H, et al. Prevalence rate of depression in Chinese elderly from 2010 to 2019: a meta-analysis. Chinese Journal of Evidence-Based Medicine. 2020;20(1):26-31. 
9. Brandao DJ, Fontenelle LF, da Silva SA, Menezes PR, Pastor-Valero M. Depression and excess mortality in the elderly living in low and middle-income countries: Systematic review and metaanalysis. Int J Geriatr Psychiatry. 2019;34(1):22-30.

10. Bock JO, Hajek A, Weyerer S, Werle J, Wagner M, Maier W, et al. The Impact of Depressive Symptoms on Healthcare Costs in Late Life: Longitudinal Findings From the AgeMooDe Study. Am J Geriatr Psychiatry. 2017;25(2):131-41.

11. Hall CA, Reynolds-lii CF. Late-life depression in the primary care setting: challenges, collaborative care, and prevention. Maturitas. 2014;79(2):147-52.

12. Taheri Tanjanai P, Moradinazar M, Najafi F. Prevalence of depression and related social and physical factors amongst the Iranian elderly population in 2012. Geriatr Gerontol Int. 2017;17(1):126-31.

13. Ge L, Yap CW, Ong R, Heng BH. Social isolation, loneliness and their relationships with depressive symptoms: A population-based study. PLoS One. 2017;12(8):e0182145.

14. Pino EC, Damus K, Jack B, Henderson D, Milanovic S, Kalesan B. Adolescent socioeconomic status and depressive symptoms in later life: Evidence from structural equation models. J Affect Disord. 2018;225:702-8.

15. Wang H, Sun HP, Wang P, Xu Y, Pan CW. Cataract and Depressive Symptoms among Older Chinese Adults. Optom Vis Sci. 2016;93(12):1479-84.

16. Ruiz M, Malyutina S, Pajak A, Kozela M, Kubinova R, Bobak M. Congruent relations between perceived neighbourhood social cohesion and depressive symptoms among older European adults: An East-West analysis. Soc Sci Med. 2019;237:112454.

17. Carter T, Morres ID, Meade O, Callaghan P. The Effect of Exercise on Depressive Symptoms in Adolescents: A Systematic Review and Meta-Analysis. J Am Acad Child Adolesc Psychiatry. 2016;55(7):580-90.

18. Kong D, Solomon P, Dong X. Depressive Symptoms and Onset of Functional Disability Over 2 Years: A Prospective Cohort Study. J Am Geriatr Soc. 2019;67(S3):538-44.

19. Su P, Ding H, Zhang W, Duan G, Yang Y, Chen R, et al. The association of multimorbidity and disability in a community-based sample of elderly aged 80 or older in Shanghai, China. BMC Geriatr. 2016;16(1):178.

20. World Health Organization. WHO Global Disability Action Plan 2014-2021: Better Health for All People with Disability; World Health Organization: Gevena, Switzerland;2015.

21. Hajjioui A, Abda N, Guenouni R, Nejjari C, Fourtassi M. Prevalence of disability in Morocco: Results from a large-scale national survey. J Rehabil Med. 2019;51(10):805-12.

22. Hermsen LA, Leone SS, Smalbrugge M, Dekker J, van der Horst HE. Frequency, severity and determinants of functional limitations in older adults with joint pain and comorbidity: Results of a cross-sectional study. Arch Gerontol Geriatr. 2014;59(1):98-106.

23. Okoro CA, Hollis ND, Cyrus AC, Griffin-Blake S. Prevalence of Disabilities and Health Care Access by Disability Status and Type Among Adults-United States, 2016. Morb Mortal Wkly Rep. 2018;67(32):882-7. 
24. Lestari SK, Ng N, Kowal P, Santosa A. Diversity in the Factors Associated with ADL-Related Disability among Older People in Six Middle-Income Countries: A Cross-Country Comparison. Int J Environ Res Public Health. 2019;16(8):1341.

25. Cwirlej-Sozanska AB, Sozanski B, Wisniowska-Szurlej A, Wilmowska-Pietruszyńska A. An assessment of factors related to disability in $A D L$ and IADL in elderly inhabitants of rural areas of south-eastern Poland. Ann Agric Environ Med. 2018;25(3):504-11.

26. Dai HL, Yu ZB, You LQ, Fan MH, Zhu HW, Jiang DJ, et al. Association between social health status and depressive symptoms among community-dwelling elderly adults in Zhejiang Province, China. $J$ Zhejiang Univ Sci B. 2019;20(11):910-9.

27. Kojima G. Frailty as a predictor of disabilities among community-dwelling older people: A systematic review and meta-analysis. Disabil Rehabilit. 2017;39(19):1897-908.

28. Kilavuz A, Meseri R, Savas S, Simsek H, Sahin S, Bicakli DH, et al. Association of sarcopenia with depressive symptoms and functional status among ambulatory community-dwelling elderly. Arch Gerontol Geriatr. 2018;76:196-201.

29. Mutambudzi M, Chen NW, Markides KS, Al Snih S. Effects of Functional Disability and Depressive Symptoms on Mortality in Older Mexican-American Adults with Diabetes Mellitus. J Am Geriatr Soc. 2016;64(11):e154-9.

30. Yesavage JA, Brink TL, Rose TL, Lum O, Huang V, Adey M, et al. Development and validation of a geriatric depression screening scale: a preliminary report. J Psychiatr Res. 1982;17(1):37-49.

31. Dong Q, Liu JJ, Zheng RZ, Dong YH, Feng XM, Li J, et al. Obesity and depressive symptoms in the elderly: A survey in the rural area of Chizhou, Anhui province. Int J Geriatr Psychiatry. 2013;28(3):227-32.

32. Rong J, Chen G, Wang X, Ge Y, Meng N, Xie T, et al. Correlation between depressive symptoms and quality of life, and associated factors for depressive symptoms among rural elderly in Anhui, China. Clin Interv Aging. 2019;14:1901-10.

33. Üstun TB, Ebrary I. Measuring health and disability: manual for WHO Disability Assessment Schedule WHODAS 2.0. Geneva:WHO;2010.

34. World Health Organization. International classification of functioning, disability and health (ICF). Geneva:WHO;2001.

35. Machuca C, Vettore MV, Krasuska M, Baker SR, Robinson PG. Using classification and regression tree modelling to investigate response shift patterns in dentine hypersensitivity. BMC Med Res Methodol. 2017;17(1):120.

36. Dong X, Zhao L, Sun T, Yun F, Qiu L. Prevalence of Depressive Symptoms and Associated Factors among Internal Migrants with Tuberculosis: A Cross-Sectional Study in China. Am J Trop Med Hyg. 2020;102(1):31-5.

37. Park JI, Park TW, Yang JC, Chung SK. Factors associated with depression among elderly Koreans: The role of chronic illness, subjective health status, and cognitive impairment. Psychogeriatrics. 2016;16(1):62-9. 
38. Ortiz GG, Arias-Merino ED, Flores-Saiffe ME, elázquez-Brizuela IE, Macías-Islas MA, Pacheco-Moisés FP. Prevalence of Cognitive Impairment and Depression among a Population Aged over 60 Years in the Metropolitan Area of Guadalajara, Mexico. Curr Gerontol Geriatr Res. 2012;2012:175019.

39. Lou VW, Chi I, Kwan CW, Leung AY. Trajectories of social engagement and depressive symptoms among long-term care facility residents in Hong Kong. Age Ageing. 2013;42(2):215-22.

40. Kuroda A, Tanaka T, Hirano H, Ohara Y, Kikutani T, Furuya H, et al. Eating Alone as Social Disengagement is Strongly Associated with Depressive Symptoms in Japanese Community-Dwelling Older Adults. J Am Med Dir Assoc. 2015;16(7):578-85.

41. Lee J, Jang SN, Cho SI. Gender differences in the trajectories and the risk factors of depressive symptoms in later life. Int Psychogeriatr. 2017;29(9):1495-505.

42. Van den Brink R, Schutter N, Hanssen D, Elzinga BM, Rabeling-Keus IM, Stek ML, et al. Prognostic significance of social network, social support and loneliness for course of major depressive disorder in adulthood and old age. Epidemiol Psychiatr Sci. 2018;27(3):266-77.

43. Zahodne LB, Watson CW, Seehra S, Martinez MN. Positive Psychosocial Factors and Cognition in Ethnically Diverse Older Adults. J Int Neuropsychol Soc. 2018;24(3):294-304.

44. Kilzieh N, Rastam S, Ward KD, Maziak W. Gender, depression and physical impairment: an epidemiologic perspective from Aleppo, Syria. Soc Psychiatry Psychiatr Epidemiol. 2010;45(6):595602.

45. Tomioka K, Kurumatani N, Hosoi H. Association Between Social Participation and 3-Year Change in Instrumental Activities of Daily Living in Community-Dwelling Elderly Adults. J Am Geriatr Soc. 2017;65(1):107-13.

46. Ismail Z, Smith EE, Geda Y, Sultzer D, Brodaty H, Smith G, et al. Neuropsychiatric symptoms as early manifestations of emergent dementia: Provisional diagnostic criteria for mild behavioral impairment. Alzheimers Dement. 2016;12(2):195-202.

47. Lara E, Koyanagi A, Domènech-Abella J, Miret M, Ayuso-Mateos JL, Haro JM. The Impact of Depression on the Development of Mild Cognitive Impairment over 3 Years of Follow-Up: A Population-Based Study. Dement Geriatr Cogn Disord. 2017;43(3-4):155-69.

48. Youn H, Lee ES, Lee S, Suh S, Jeong HG, Eo JS. Regional glucose metabolism due to the presence of cerebral amyloidopathy in older adults with depression and mild cognitive impairment. J Affect Disord. 2018;239:30-6.

49. Del Brutto OH, Mera RM, Del Brutto VJ, Maestre GE, Gardener H, Zambrano M, et al. Influence of depression, anxiety and stress on cognitive performance in community-dwelling older adults living in rural Ecuador: results of the Atahualpa Project. Geriatr Gerontol Int. 2015;15(4):508-14.

50. Lou CY, Wu KY, Shen S, Ying LY. Investigation and analysis of depression and cognitive status of elderly people in aged care institutions in urban area of Hangzhou. Chin J Mod Nurs. 2019;25(1):726.

51. Gale CR, Allerhand M, Deary IJ, HALCyon Study Team. Is there a bidirectional relationship between depressive symptoms and cognitive ability in older people? A prospective study using the English 
Longitudinal Study of Ageing. Psychol Med. 2012;42(10):2057-69.

52. Hernández-Vásquez A, Vargas-Fernández R, Bendezu-Quispe G, Grendas LN. Depression in the Peruvian population and its associated factors: analysis of a national health survey. J Affect Disord. 2020;273:291-7.

53. Xiong N, Liu Q, Lv X, Leonhart R, Tian H, Wei J, et al. Demographic and Psychosocial Variables Could Predict the Occurrence of Major Depressive Disorder, but Not the Severity of Depression in Patients with First-episode Major Depressive Disorder in China. J Affect Disord. 2020;274:103-11.

54. Xiang X, Yang Y, Cheng J, An R. The Impact of Late-life Disability Spectrum on Depressive Symptoms: A Fixed-Effects Analysis of Panel Data. J Gerontol B Psychol Sci Soc Sci. 2020.

\section{Tables}


Table 1 Demographic characteristics of respondents, $\mathrm{n}(\%)$

\begin{tabular}{|c|c|c|c|c|c|}
\hline \multirow[t]{2}{*}{ Variables } & \multirow{2}{*}{$\begin{array}{l}\text { Total } \\
(\mathrm{N}=3336)\end{array}$} & \multicolumn{2}{|c|}{ Depressive symptoms } & \multirow[t]{2}{*}{$c^{2}$} & \multirow[t]{2}{*}{$p$-Value } \\
\hline & & $\begin{array}{l}\text { Absence } \\
(\mathrm{N}=1570)\end{array}$ & $\begin{array}{l}\text { Presence } \\
(\mathrm{N}=1766)\end{array}$ & & \\
\hline Gender & & & & 93.252 & $<0.001$ \\
\hline Male & $\begin{array}{l}1640 \\
(49.2)\end{array}$ & $911(58.0)$ & 729 (41.3) & & \\
\hline Female & $\begin{array}{l}1696 \\
(50.8)\end{array}$ & $659(42.0)$ & $1037(58.7)$ & & \\
\hline Age (years) & & & & 68.899 & $<0.001$ \\
\hline $60-69$ & $\begin{array}{l}1529 \\
(45.8)\end{array}$ & $808(51.5)$ & $721(40.8)$ & & \\
\hline $70-79$ & $\begin{array}{l}1325 \\
(39.7)\end{array}$ & $611(38.9)$ & $714(40.4)$ & & \\
\hline$\geq 80$ & $482(14.5)$ & $151(9.6)$ & 331 (18.8) & & \\
\hline Education level & & & & 70.636 & $<0.001$ \\
\hline Illiterate & $\begin{array}{l}2211 \\
(66.3)\end{array}$ & $926(59.0)$ & $1285(72.8)$ & & \\
\hline Primary and above & $\begin{array}{l}1125 \\
(33.7)\end{array}$ & $644(41.0)$ & $481(27.2)$ & & \\
\hline Employment status & & & & 77.429 & $<0.001$ \\
\hline Unemployed & $\begin{array}{l}2137 \\
(64.1)\end{array}$ & $884(56.3)$ & $1253(71.0)$ & & \\
\hline Employed & $\begin{array}{l}1199 \\
(35.9)\end{array}$ & $686(43.7)$ & $513(29.0)$ & & \\
\hline Living style & & & & 2.102 & 0.350 \\
\hline Living alone & $660(19.8)$ & $294(18.7)$ & 366 (20.7) & & \\
\hline Living with spouse & $\begin{array}{l}1436 \\
(43.0)\end{array}$ & $686(43.7)$ & 750 (42.5) & & \\
\hline Others & $\begin{array}{l}1240 \\
(37.2)\end{array}$ & $590(37.6)$ & $650(36.8)$ & & \\
\hline Region & & & & 98.127 & $<0.001$ \\
\hline Northern & $\begin{array}{l}1482 \\
(44.4)\end{array}$ & $558(35.5)$ & $924(52.3)$ & & \\
\hline Central & $919(27.5)$ & $482(30.7)$ & $437(24.7)$ & & \\
\hline Southern & $935(28.1)$ & $530(33.8)$ & $405(23.0)$ & & \\
\hline
\end{tabular}




\begin{tabular}{|c|c|c|c|c|c|}
\hline Poverty & & & & 66.057 & $<0.001$ \\
\hline Yes & $\begin{array}{l}1206 \\
(36.2)\end{array}$ & $455(29.0)$ & $751(42.5)$ & & \\
\hline No & $\begin{array}{l}2130 \\
(63.8)\end{array}$ & 1115 (71.0) & 1015 (57.5) & & \\
\hline $\begin{array}{l}\text { Physical } \\
\text { discomfort }\end{array}$ & & & & 114.886 & $<0.001$ \\
\hline Yes & $\begin{array}{l}2120 \\
(63.5)\end{array}$ & $849(54.1)$ & $1271(72.0)$ & & \\
\hline No & $\begin{array}{l}1216 \\
(36.5)\end{array}$ & $721(45.9)$ & $495(28.0)$ & & \\
\hline Chronic diseases & & & & 46.781 & $<0.001$ \\
\hline No & $864(25.9)$ & 493 (31.4) & $371(21.0)$ & & \\
\hline Yes & $\begin{array}{l}2472 \\
(74.1)\end{array}$ & 1077 (68.6) & 1395 (79.0) & & \\
\hline Hospitalization & & & & 84.982 & $<0.001$ \\
\hline Yes & $\begin{array}{l}1062 \\
(31.8)\end{array}$ & $376(23.9)$ & $686(38.8)$ & & \\
\hline No & $\begin{array}{l}2274 \\
(68.2)\end{array}$ & $1194(76.1)$ & $1080(61.2)$ & & \\
\hline
\end{tabular}


Table 2 Distribution of functional disability among subjects

\begin{tabular}{|c|c|c|c|c|c|c|c|}
\hline \multirow[t]{3}{*}{ Disability } & \multirow{2}{*}{\multicolumn{2}{|c|}{ Total $(\mathrm{N}=3336)$}} & \multicolumn{4}{|c|}{ Depressive symptoms } & \multirow{3}{*}{$\begin{array}{l}p- \\
\text { Value }^{\mathrm{b}}\end{array}$} \\
\hline & & & \multicolumn{2}{|c|}{ Absence $(\mathrm{N}=1570)$} & \multicolumn{2}{|c|}{ Presence $(\mathrm{N}=1766)$} & \\
\hline & $\mathrm{GM}^{\mathrm{a}}$ & Median (IQR) & GM & Median (IQR) & GM & Median (IQR) & \\
\hline Cognition & 15.39 & $\begin{array}{l}5.00 \\
(0.00,25.00)\end{array}$ & 9.98 & $\begin{array}{l}5.00 \\
(0.00,15.00)\end{array}$ & 20.21 & $\begin{array}{l}15.00 \\
(5.00,35.00)\end{array}$ & $<0.001$ \\
\hline Mobility & 26.57 & $\begin{array}{l}18.75 \\
(0.00,43.75)\end{array}$ & 15.33 & $\begin{array}{l}0.00 \\
(0.00,25.00)\end{array}$ & 36.57 & $\begin{array}{l}37.50 \\
(12.50,56.25)\end{array}$ & $<0.001$ \\
\hline Self-care & 11.33 & $\begin{array}{l}0.00 \\
(0.00,10.00)\end{array}$ & 4.87 & $\begin{array}{l}0.00 \\
(0.00,0.00)\end{array}$ & 17.07 & $\begin{array}{l}0.00 \\
(0.00,40.00)\end{array}$ & $<0.001$ \\
\hline $\begin{array}{l}\text { Getting } \\
\text { along }\end{array}$ & 14.61 & $\begin{array}{l}0.00 \\
(0.00,31.25)\end{array}$ & 7.33 & $\begin{array}{l}0.00 \\
(0.00,0.00)\end{array}$ & 21.08 & $\begin{array}{l}10.42 \\
(0.00,41.67)\end{array}$ & $<0.001$ \\
\hline $\begin{array}{l}\text { Life } \\
\text { activities }\end{array}$ & 31.91 & $\begin{array}{l}30.00 \\
(0.00,40.00)\end{array}$ & 19.83 & $\begin{array}{l}0.00 \\
(0.00,40.00)\end{array}$ & 42.64 & $\begin{array}{l}40.00 \\
(30.00,50.00)\end{array}$ & $<0.001$ \\
\hline Participation & 29.39 & $\begin{array}{l}25.00 \\
(12.50,41.67)\end{array}$ & 18.06 & $\begin{array}{l}16.67 \\
(4.17,25.00)\end{array}$ & 39.46 & $\begin{array}{l}33.33 \\
(25.00,50.00)\end{array}$ & $<0.001$ \\
\hline
\end{tabular}
a GM stands for geometric mean
b p values were derived from Mann-Whitney $U$ tests

\section{Figures}




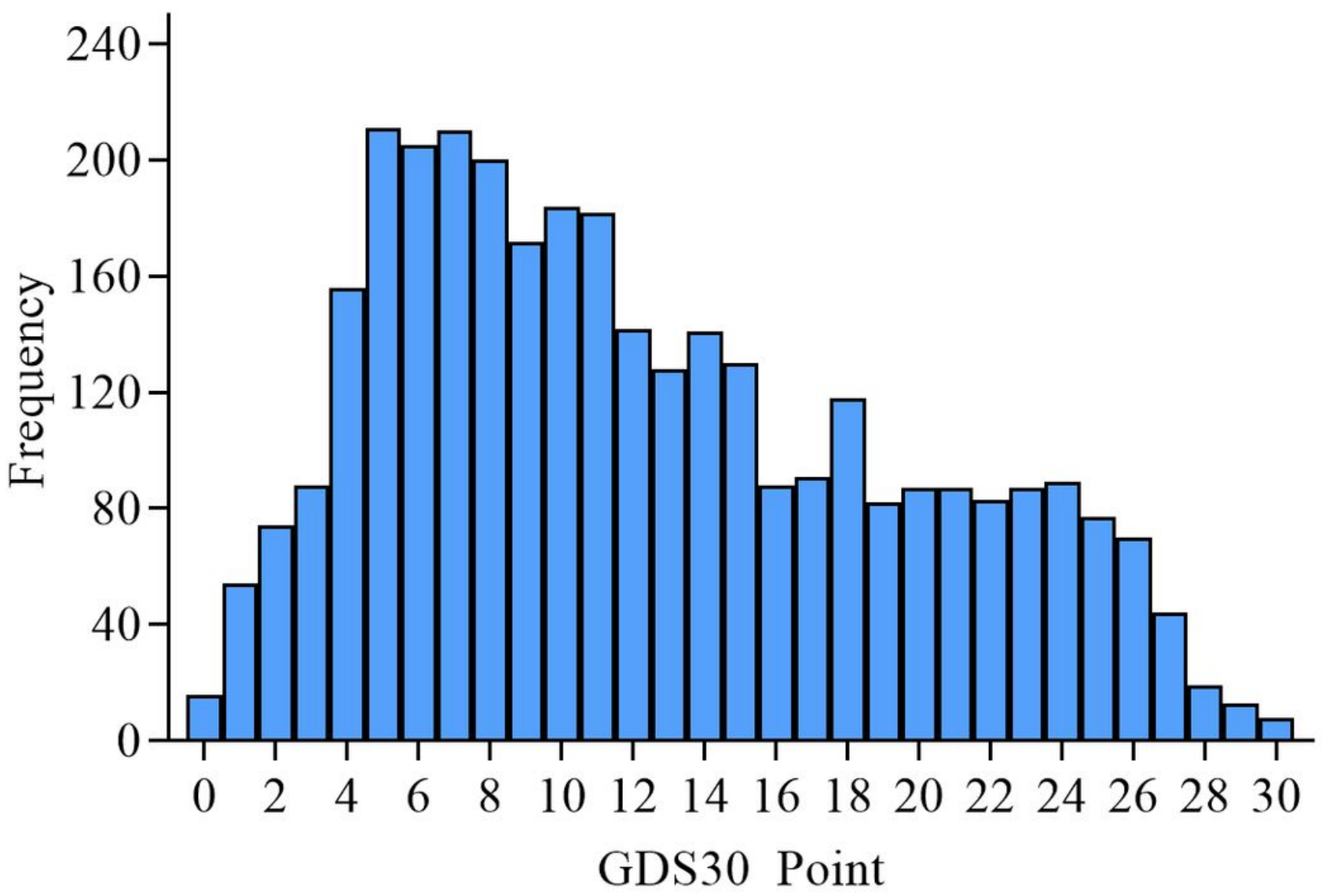

Figure 1

GDS-30 score distribution of the subjects. 
Participation(withproblem) Reference catagory: no problem

Lifeactivities(withproblem) Reference catagory: no problem

Getting along (with problem) Reference catagory: no problem

Self care (with problem) Reference catagory: no problem

Mobility (with problem) Reference catagory: no problem

Cognition (with problem) Reference catagory: no problem

Hospitalization (No) Reference catagory: Yes

Chronic diseases (Yes) Reference catagory: No

Physical discomfort (No) Reference catagory: Yes

Poverty (No) Reference catagory: Yes

Region (Southern) Reference catagory: Northern

Region (Central) Reference catagory: Northern

Livingstyle (Living with Other) Reference catagory: Living alone

Living style (Living with spouse) Reference catagory: Living alone

Employment status (Employed) Reference catagory: Unemployed

Education level (Primary and above) Reference catagory: Illiterate

Age ( $\$ 80$ years) Reference catagory: 60-69 years

Age (70-79years) Reference catagory: 60-69 years

Gender (Female) Reference catagory: Male gender

Ther




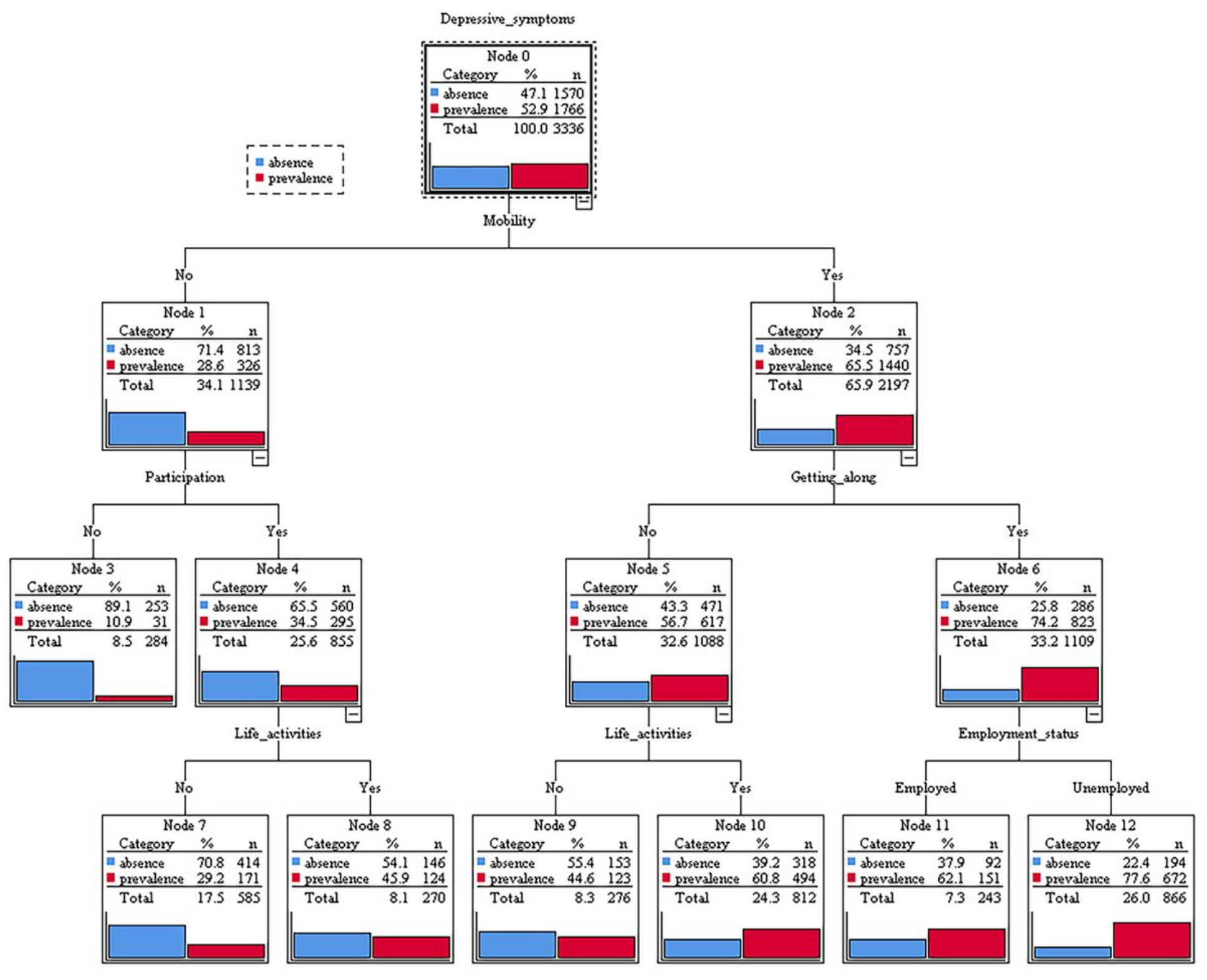

\section{Figure 3}

Classification and regression tree model $(\mathrm{N}=3336)$.

\section{Supplementary Files}

This is a list of supplementary files associated with this preprint. Click to download.

- TableS2.doc

- TableS1.doc

- STROBEchecklist.docx 